\title{
Current Total Knee Designs: Does Baseplate Roughness or Locking Mechanism Design Affect Polyethylene Backside Wear?
}

\author{
Zachary W. Sisko MD, Matthew G. Teeter PhD, Brent A. Lanting MD, MSc, FRCSC, \\ James L. Howard MD, MSc, FRCSC, Richard W. McCalden MD, FRCSC, \\ Douglas D. Naudie MD, FRCSC, Steven J. MacDonald MD, FRCSC, \\ Edward M. Vasarhelyi MD, MSc, FRCSC
}

Received: 30 November 2016/Accepted: 31 August 2017/Published online: 13 September 2017

(C) The Association of Bone and Joint Surgeons \& 2017

\begin{abstract}
Background Tibial baseplate roughness and polyethylene-insert micromotion resulting from lockingmechanism loosening can lead to polyethylene backside wear in TKAs. However, many retrieval studies examining these variables have evaluated only older TKA implant designs.

Questions We used implant-retrieval analysis to examine if there were differences in: (1) backside damage scores,
\end{abstract}

The institution of one or more of the authors (MGT, BAL, JLH, RWM, DDN, SJM, EMV) has received during the study period funding from Smith \& Nephew (Memphis, TN, USA), DePuy (Warsaw, IN, USA), Stryker (Mahwah, NJ, USA), Zimmer (Warsaw, IN, USA), and Microport (Arlington, TN, USA).

One of the authors certifies that he (BAL) or a member of his immediate family has received, during the study period, an amount of less than USD 10,000 from DePuy (Warsaw, IN, USA), Integra (Plainsboro, NJ, USA), an amount of less than USD 10,000 from Intellijoint (Waterloo, ON, Canada), and an amount of less than USD 10,000 from Stryker (Mahwah, NJ, USA); and grants in an amount USD 10,001 to USD 100,000 from DePuy (Warsaw, IN, USA); an amount USD 10,001 to USD 100,000 from Microport (Arlington, TX, USA), an amount USD 10,001 to USD 100,000 from Stryker (Mahwah, NJ, USA), and an amount less than USD 10,000 from Zimmer (Warsaw, IN, USA).

One of the authors certifies that he (JLH) or a member of his immediate family has received during the study period, an amount of less than USD 10,000 from DePuy (Warsaw, IN, USA) and an amount of USD 10,001 to USD 100,000 from Stryker (Mahwah, NJ, USA). One of the authors certifies that he (RWM) or a member of his immediate family has received during the study period, an amount of USD 100,001 to USD 1,000,000, from Smith \& Nephew (Memphis, TN, USA).

One of the authors certifies that he (DDN) or a member of his immediate family has received during the study period, an amount of USD 10,001 to USD 100,000 from Exactech (Gainesville, FL, USA), an amount of USD 10,001 to USD 100,000 from Smith \& Nephew (Memphis, TN, USA), an amount of USD 10,001 to USD 100,000 from Stryker (Mahwah, NJ, USA), and an amount of USD 10,001 to
(2) backside damage modes, and (3) backside linear wear rates in five TKA implant designs owing to differing baseplate surface roughness and locking mechanisms. Additionally, we examined if (4) patient demographics influence backside damage and wear.

Methods Five TKA implant models (four modern and one historical design) were selected with different tibial baseplate and/or locking mechanism designs. Six tibial inserts retrieved at the time of revision from each TKA model were matched for time in vivo, age of the patient at TKA

USD 100,000 from Zimmer (Warsaw, IN, USA).

One of the authors certifies that he (SJM) or a member of his immediate family has received during the study period, an amount of USD 100,001 to USD 1,000,000 from DePuy (Warsaw, IN, USA). One of the authors certifies that he (EMV) or a member of his immediate family has received during the study period, an amount of less than USD 10,000 from (DePuy, Warsaw, IN, USA). All ICMJE Conflict of Interest Forms for authors and Clinical Orthopaedics and Related Research ${ }^{\mathbb{B}}$ editors and board members are on file with the publication and can be viewed on request.

Each author certifies that his institution approved the human protocol for this investigation and that all investigations were conducted in conformity with ethical principles of research.

This work was performed at London Health Sciences Centre and the Schulich School of Medicine \& Dentistry at Western University, University Hospital (London, Ontario, Canada).

Z. W. Sisko, M. G. Teeter, B. A. Lanting, J. L. Howard, R. W. McCalden, D. D. Naudie, S. J. MacDonald,

E. M. Vasarhelyi

Division of Orthopaedic Surgery, Department of Surgery, London Health Sciences Centre and the Schulich School of Medicine \& Dentistry at Western University, University Hospital, London, ON, Canada

\section{Z. W. Sisko $(\bowtie)$}

Pittsburgh Bone, Joint \& Spine, Inc., Allegheny Health Network, 1200 Brooks Lane, Suite G-20, Jefferson Hills, PA 15025, USA e-mail: Zachary.Sisko@ahn.org 
revision, BMI, sex, revision number, and revision reason. Each insert backside was analyzed for: (1) visual total damage score and (2) individual visual damage modes, both by two observers and with an intraclass correlation coefficient of 0.66 (95\% CI, 0.39-0.92), and (3) linear wear rate measured by micro-CT. Median primary outcomes were compared among the five designs. For our given sample size among five groups we could detect with $80 \%$ power a 10-point difference in damage score and an 0.11$\mathrm{mm}$ per year difference in wear rate.

Results The polished tibial design with a partial peripheral capture locking mechanism and anterior constraint showed a lower total damage score compared with the nonpolished tibial design with only a complete peripheralrim locking mechanism (median, 12.5; range, 9.5-18.0; 95\% CI, 9.58-16.42 versus median, 22.3; range, 15.5-27.0; 95\% CI, 17.5-26.5; $\mathrm{p}=0.019$ ). The polished baseplate with a tongue-in-groove locking mechanism showed more abrasions than the nonpolished baseplate with a peripheralrim capture and antirotational island (median, 7.25; range, 0.5-8.0; 95\% CI, 2.67-8.99 versus median, 0.75; range, 0$1.5 ; 95 \% \mathrm{CI}, 0.20-1.47 ; \mathrm{p}=0.016)$ ). Dimpling was a unique wear mode to the nonpolished baseplates with the peripheral-rim capture and antirotational island (median, 5.5; range, 2.0-9.0; 95\% CI, 2.96-8.38) and the peripheralrim capture alone (median, 9.0; range, 6.0-10.0; 95\% CI, 7.29-10.38). Overall, the linear wear rate for polished designs was lower than for nonpolished designs $(0.0102 \pm$ $0.0044 \mathrm{~mm} /$ year versus $0.0224 \pm 0.0119 \mathrm{~mm} /$ year; $\mathrm{p}<$ 0.001). Two of the polished baseplate designs, the partial peripheral capture with anterior constraint (median, 0.083 $\mathrm{mm} /$ year; range, 0.0037-0.0111 $\mathrm{mm} /$ year; 95\% CI, $0.0050-0.0107 \mathrm{~mm}$ versus median, $0.0245 \mathrm{~mm} /$ year; range, 0.014-0.046 mm/year; 95\% CI, $0.0130-0.0414 \mathrm{~mm}$; $\mathrm{p}=$ $0.008)$ and the tongue-in-groove locking mechanism (median, $0.0085 \mathrm{~mm} /$ year; range, $0.005-0.015 \mathrm{~mm} /$ year; 95\% CI, $0.0045-0.0138 \mathrm{~mm} ; \mathrm{p}=0.032$ ) showed lower polyethylene linear wear rates compared with the nonpolished baseplate design with only a peripheral-rim capture. Conclusions Total damage scores and linear wear rates were highest involving the nonpolished design with only a peripheral rim capture. There were no differences among the other TKA designs regarding damage and wear, but this finding should be considered in the setting of a relatively small sample size.

Clinical Relevance Our study showed that in the complex interplay between baseplate surface finish and locking mechanism design, a polished baseplate with a robust locking mechanism had the lowest backside damage and linear wear. However, improvements in locking mechanism design in nonpolished baseplates potentially may offset some advantages of a polished baseplate. Further retrieval analyses need to be done to confirm such findings, especially analyzing current crosslinked polyethylene. Additionally, we need mid- and long-term studies comparing TKA revisions attributable to wear and osteolysis among implants before understanding if such design differences are clinically relevant.

\section{Introduction}

One common cause of TKA revision is polyethylene wear and/or resultant osteolysis. With older TKA implant designs, these modes were reported as the primary cause of revision in $30 \%$ to $44 \%$ of TKAs during the 2 years after the index procedure [20,37]. More-current analyses of primary TKA failures attribute polyethylene wear and/or osteolysis as a cause of revision in a much lower percentage $-4 \%$ to $10 \%$ of revisions $[35,38]$. Improvements in wear and/or osteolysis-related revision rates are attributed to changes in polyethylene manufacturing, sterilization, and crosslinking [9, 25], along with more robust tibial baseplate locking mechanisms decreasing insert micromotion [24]. Nonetheless, it is crucial to understand what aspects of current baseplate and locking mechanism design contribute to issues that lead to a notable percentage of revision TKAs.

Metal-backed modular tibial components initially were introduced to improve tibial fixation, decrease aseptic loosening, add thickness and constraint options for the tibial insert, and theoretically facilitate ease of revision surgery [12]. However, the introduction of modular TKA implants has caused unintended consequences. For example, in many instances, the nonarticulating tibial insert undersurface in modular designs can produce even larger amounts of polyethylene wear and debris particles [26, 46] than the polyethylene tibiofemoral articulating surface [39]. This so-called "backside wear" similarly led to osteolysis [7, 14] in multiple cemented [28, 33] and noncemented [11, 34] implants.

A recent retrieval study [40] showed a strong association between increased backside polyethylene wear and increasing tibial baseplate surface roughness. This correlation is corroborated in multiple other retrieval studies $[1,3,4,18]$. There also are varying degrees of evidence that backside wear is increased by other implant factors such as polyethylene sterilization in noninert gas $[2,5,6,9,25,40]$, polyethylene manufacturing [16, 27], tibial baseplate composition $[3,4,7]$, conformity of the polyethylene articular surface [36], and polyethylene thickness [13, 44]. In some studies, patient factors such as longer time in vivo of the polyethylene [17, 21, 31], increased patient weight [8], male sex, and younger patient age [16] have been shown to increase backside wear. Surgeon-specific variables like component alignment and 
positioning [29, 44, 45] also have influenced backside insert wear, although the evidence is less compelling.

TKA implant designs limit backside wear owing to the strength and integrity of the locking mechanism between the polyethylene and tibial baseplate [7]. Engh et al. [15] showed that various locking mechanism designs loosen with time leading to backside polyethylene wear. Furthermore, robust locking mechanisms that limit micromotion between the polyethylene backside and baseplate will limit the amount of backside wear [30, 31]. However, much of the data regarding retrieved polyethylene backside damage arise from older TKA implants [6-8, 26, 29, 30, 39, 40, 45, 46].

In this study, we used implant-retrieval analysis to examine if there are differences in (1) backside damage scores, (2) backside damage modes, and (3) backside linear wear rates in four modern TKA implant designs and one historical control attributable to tibial baseplate surface roughness and locking mechanisms. Additionally, we examined if (4) patient demographics influence backside insert damage and wear.

\section{Materials and Methods}

The study was initiated after approval from the institutional research ethics board of Western University.

Five different implant designs were selected for comparison from the institutional implant retrieval laboratory that holds approximately 20 primary TKA implant designs and more than 1500 available implants. The basis for selection centered on differences in tibial baseplate surface and/or locking mechanism design, along with implant availability in our institutional retrieval laboratory to permit cohort matching among groups. The systems evaluated included a historical design, (1) The Anatomic
Modular Knee ${ }^{\circledR}$ (AMK) (DePuy, Warsaw, IN, USA) (140 total available AMK implants in the retrieval laboratory), involved in previous retrieval analyses for backside wear $[7,8,26,40]$ and locking mechanism strength [15, 30, 31], even though it is not currently in clinical use. The other four TKA systems evaluated were identified as modern designs in that they were still in clinical use at the beginning of the study period (study period, August 1, 2015 to July 31, 2016). These modern designs (with number of total implants available from which to choose in our retrieval laboratory included: (2) the Sigma ${ }^{\circledR}$ Total Knee system (DePuy, Warsaw, IN, USA) (105 implants), (3) the Scorpio ${ }^{\circledR}$ Total Knee system (Stryker, Mahwah, NJ, USA) (49 implants), (4) the Triathlon $^{\circledR}$ Total Knee system (Stryker, Mahwah, NJ, USA) (71 implants), and (5) the Genesis ${ }^{\circledR}$ II Total Knee system (Smith \& Nephew, Memphis, TN, USA) (179 implants) (Table 1). The designs selected represent examples of implants with polished and unpolished tibial baseplates and various locking mechanisms (Fig. 1). Regarding locking mechanism strength, the partial peripheral capture with anterior constraint of the Genesis II has performed well in previous retrieval studies [1, 2]. Biomechanical studies have shown the relatively greater strength of a full peripheral-rim capture when compared with the tongue-in-groove locking mechanism of the AMK design [7, 15, 30]. To the best of our knowledge, the peripheral-rim capture with the addition of a central antirotational island has not been studied, but theoretically should better limit backsurface micromotion compared with a peripheral-rim capture alone.

For each of the five implant designs, six polyethylene inserts were cohort matched based on time in vivo, patient age at revision, BMI, sex, the revision number at explantation, and the reason for revision. Sample size was

Table 1. TKA implant models

\begin{tabular}{|c|c|c|c|c|}
\hline $\begin{array}{l}\text { TKA } \\
\text { model }\end{array}$ & $\begin{array}{l}\text { Tibial } \\
\text { baseplate } \\
\text { design }\end{array}$ & $\begin{array}{l}\text { Tibial baseplate } \\
\text { composition }\end{array}$ & $\begin{array}{l}\text { Tibial baseplate } \\
\text { roughness (Ra) }\end{array}$ & Locking mechanism design \\
\hline $\begin{array}{l}\text { AMK }^{\mathbb{B}} \text { (DePuy, Warsaw, IN, } \\
\text { USA) }\end{array}$ & Polished & Cobalt-chrome & $<0.10 \mu \mathrm{m}$ & Anterior tongue-in-groove with central locking pin \\
\hline $\begin{array}{l}\text { Sigma }^{\circledR} \\
\text { USA) }\end{array}$ & Polished & Cobalt-chrome & $<0.35 \mu \mathrm{m}$ & Full peripheral capture \\
\hline $\begin{array}{l}\text { Scorpio }^{\circledR} \text { (Stryker, Mahwah, } \\
\text { NJ, USA) }\end{array}$ & Nonpolished & Cobalt-chrome & $<2 \mu \mathrm{m}$ & $\begin{array}{l}\text { Complete peripheral rim capture with three anterior barbs } \\
\text { for insert wire }\end{array}$ \\
\hline $\begin{array}{l}\text { Triathlon }{ }^{\circledR} \text { (Stryker, Mahwah, } \\
\text { NJ, USA) }\end{array}$ & Nonpolished & Cobalt-chrome & $<4 \mu \mathrm{m}$ & $\begin{array}{l}\text { Complete peripheral rim capture with central antirotational } \\
\text { island and three anterior barbs for insert wire }\end{array}$ \\
\hline $\begin{array}{l}\text { Genesis }^{\circledR} \text { II (Smith \& } \\
\text { Nephew, Memphis, TN, } \\
\text { USA) }\end{array}$ & Polished & Titanium & $<0.08 \mu \mathrm{m}$ & $\begin{array}{l}\text { Partial peripheral capture with posterior lipped edge and } \\
\text { anterior constraint }\end{array}$ \\
\hline
\end{tabular}



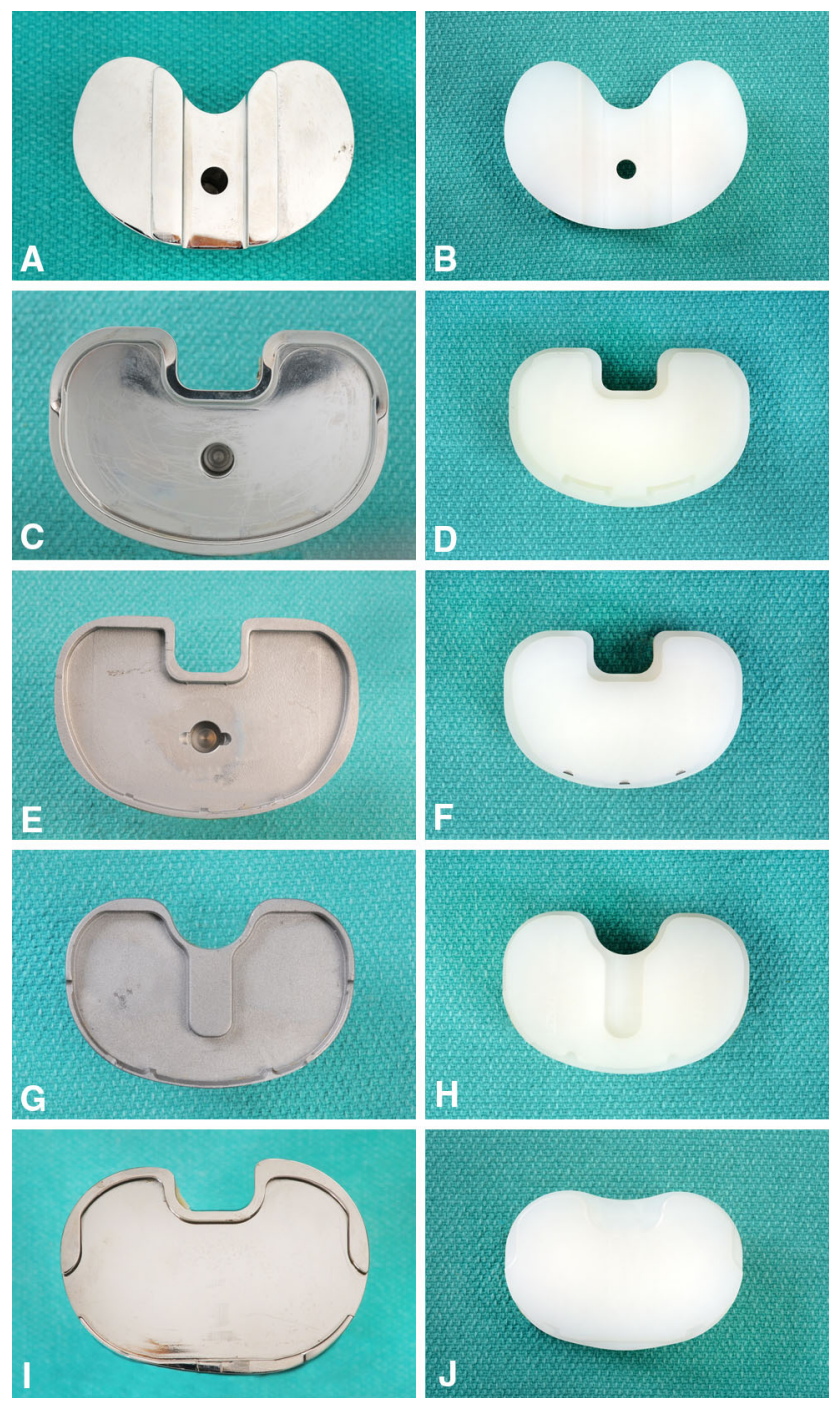

Fig. 1A-J Shown are: (A) a retrieved AMK polished cobalt-chrome tibial baseplate with a tongue-in-groove locking mechanism design; (B) the backside of a retrieved AMK polyethylene insert with grooves noted for the locking mechanism; (C) a retrieved Sigma polished cobalt-chrome tibial baseplate with full peripheral-rim capture locking mechanism design; (D) the backside of a retrieved Sigma polyethylene insert with peripheral recess and anterior bumper for the locking mechanism; (E) a retrieved Scorpio nonpolished cobaltchrome tibial baseplate with a full peripheral-rim capture; (F) the backside of a retrieved Scorpio polyethylene insert with peripheral recess and anterior wire for the locking mechanism; (G) a retrieved Triathlon nonpolished cobalt-chrome tibial baseplate with a peripheral-rim capture and central antirotational island locking mechanism; (H) the backside of a retrieved Triathlon polyethylene insert with recess for peripheral capture, anterior wire, and central cutout for antirotational island; (I) a retrieved Genesis II polished titanium tibial baseplate with partial peripheral-rim capture and anterior constraint; and $(\mathbf{J})$ the backside of a retrieved Genesis II polyethylene insert with recesses for peripheral-rim and anterior captures.

determined in reference to a previous cohort analysis comparing backside damage scores and wear rates between implant groups that was able to determine significance
[40]. Available polyethylene inserts were excluded if time in vivo was less than 4 years or if the polyethylene was considerably damaged during extraction. All inserts were implanted after the respective manufacturer began sterilizing polyethylene in an inert environment. We attempted to consistently analyze the same noncrosslinked polyethylene in each cohort group. The AMK polyethylene was composed of ram-bar extruded GUR 1050 resin sterilized with gas plasma. The Sigma polyethylene was Gamma Vacuum Foil, a compression-molded machined GUR 1020 resin sterilized with gamma irradiation and packaged in vacuum foil. The Scorpio and Triathlon polyethylenes were mostly N2/Vac ${ }^{\mathrm{TM}}$ (Stryker), which is conventional polyethylene GUR 1050 compression molded, irradiated, and then stored in nitrogen packaging. There was one $\mathrm{X} 3{ }^{\circledR}$ retrieval in the Triathlon group, which is Stryker's highly crosslinked polyethylene. X3 is compression-molded GUR 1020 that is sequentially irradiated and annealed three times for a cumulative radiation dose of $90 \mathrm{kGy}$ and sterilized in gas plasma. The Genesis II tibial inserts were all 1020 GUR compression-molded resin sterilized in ethylene oxide. There were no differences among the five matched TKA design groups regarding time in vivo, patient age at revision, or BMI (Table 2). Sex, revision number, and revision reason also were closely matched. Effort was made to match polyethylene design, either posterior-stabilized or cruciate-retaining, among the groups. Design along with polyethylene insert thickness and size are presented (Table 3). All of the cohorts were matched based on the prior-mentioned variables before any analysis of the retrievals was done to minimize selection bias.

We visually assessed the damage modes and damage amount on the backside of each tibial insert, adapting the method established by Hood et al. [22] for the bearing surface and described in detail by Teeter et al. [40]. The polyethylene backside was divided in four quadrants: anterolateral, anteromedial, posterolateral, and posteromedial. We evaluated eight damage modes: burnishing, abrasion, creep/deformation, scratching, pitting, delamination, embedded debris, and dimpling. Harman et al. [21] described dimpling as smooth, circular indentations lacking orientation, observed when examining insert backsides mated with nonpolished tibial baseplates. Each of the eight damage modes received a score of 0 to 3 in each of the four quadrants. A score of 0 coincides with the absence of the damage mode. A score of 1 is assigned if less than $10 \%$ of the quadrant is affected by the particular mode, 2 if $10 \%$ to $50 \%$ of the quadrant shows the damage mode, and 3 if greater than $50 \%$ of the quadrant is affected by the analyzed mode. Maximum damage mode for a single insert is 12 (maximum score of 3 in all four quadrants). The maximum total damage score for a single insert is 96 (maximum score of 12 for all eight damage modes). Two 
Table 2. Implant demographics

\begin{tabular}{|c|c|c|c|c|c|c|}
\hline Parameter & $\mathrm{AMK}^{\circledR}$ & Sigma $^{\circledR}$ & Scorpio $^{\circledR}$ & Triathlon ${ }^{\circledR}$ & Genesis ${ }^{\mathbb{R}}$ II & $\mathrm{p}$ Value \\
\hline $\begin{array}{l}\text { Time in vivo* } \\
\text { (years) }\end{array}$ & $\begin{array}{l}7.5,4.3-15.2(4.9- \\
11.5)\end{array}$ & $\begin{array}{l}6.4,5.4-11.9(5.5- \\
9.5)\end{array}$ & $\begin{array}{l}8.4,4.4-10.9 \text { (5.7- } \\
10.1)\end{array}$ & $\begin{array}{l}6.8,4.6-11.5(5.2- \\
\quad 9.4)\end{array}$ & $\begin{array}{l}9.3,5.5-10.0(6.9- \\
9.9)\end{array}$ & 0.962 \\
\hline $\begin{array}{l}\text { Age at revision* } \\
\text { (years) }\end{array}$ & $61.0,57-74(58-69)$ & $\begin{array}{l}67.0,57-78(61.2- \\
72.4)\end{array}$ & $\begin{array}{l}64.0,60-73(61.1- \\
69.3)\end{array}$ & $\begin{array}{l}\text { 69.5, 65-80 (65.9- } \\
74.5)\end{array}$ & $\begin{array}{l}67.5,44-81(56.1- \\
\quad 75.3)\end{array}$ & 0.609 \\
\hline BMI $\left(\mathrm{kg} / \mathrm{m}^{2}\right)^{*}$ & $\begin{array}{c}32.9,24.6-44.7 \\
(28.4-38.8)\end{array}$ & $\begin{array}{l}32.7,28.2-39.8 \\
\quad(28.9-36.9)\end{array}$ & $\begin{array}{l}36.5,27.2-45.0 \\
\quad(30.7-42.1)\end{array}$ & $\begin{array}{c}37.5,21.6-50.8 \\
\quad(25.5-45.3)\end{array}$ & $\begin{array}{l}30.9,20.3-47.6 \\
\quad(25.4-42.2)\end{array}$ & 0.951 \\
\hline Sex (number) & & & & & & N/A \\
\hline Male & 3 & 1 & 2 & 2 & 3 & \\
\hline Female & 3 & 5 & 4 & 4 & 3 & \\
\hline Revision number & & & & & & N/A \\
\hline Primary & 5 & 6 & 6 & 6 & 5 & \\
\hline $\begin{array}{l}\text { Subsequent } \\
\text { revisions }\end{array}$ & 13 rd revision & & & & 12 nd revision & \\
\hline \multirow[t]{4}{*}{ Revision reason } & Aseptic loosening (3) & Aseptic loosening (3) & Aseptic loosening (2) & Aseptic loosening (2) & Instability (2) & N/A \\
\hline & Infection (2) & Infection (1) & Instability (2) & Infection (2) & Infection (2) & \\
\hline & Patellar clunk (1) & Wear (1) & Infection (1) & Instability (1) & Aseptic loosening (1) & \\
\hline & & Unknown (1) & Pain (1) & Patellar problem (1) & Pain (1) & \\
\hline
\end{tabular}

*Presented as median, range, and 95\% CI; N/A = not applicable.

Table 3. Polyethylene insert size, thickness, and design

\begin{tabular}{|c|c|c|c|c|}
\hline $\mathrm{AMK}^{\mathbb{R}}$ & Sigma $^{\circledR}$ & Scorpio $^{\circledR}$ & Triathlon $^{\circledR}$ & Genesis ${ }^{\circledR}$ II \\
\hline Size $2,18 \mathrm{~mm}$, PS & Size 2, $12.5 \mathrm{~mm}$, PS & Size $5,12 \mathrm{~mm}$, PS & Size 2, $11 \mathrm{~mm}, \mathrm{CR}$ & Size $1-2,13 \mathrm{~mm}, \mathrm{PS}$ \\
\hline Size $2,18 \mathrm{~mm}$, PS & Size 2, $15 \mathrm{~mm}$, PS & Size 7, $10 \mathrm{~mm}, \mathrm{PS}$ & Size $3,9 \mathrm{~mm}$, PS & Size $3-4,11 \mathrm{~mm}$, PS \\
\hline Size $3,12 \mathrm{~mm}$, PS & Size 2, $19 \mathrm{~mm}$, PS & Size 7, $12 \mathrm{~mm}, \mathrm{CR}$ & Size $3,10 \mathrm{~mm}$, PS & Size $3-4,18 \mathrm{~mm}$, PS \\
\hline Size $3,18 \mathrm{~mm}$, PS & Size $2.5,15 \mathrm{~mm}$, PS & Size $9,8 \mathrm{~mm}, \mathrm{PS}$ & Size 4, $11 \mathrm{~mm}$, PS & Size 5-6, $9 \mathrm{~mm}$, PS \\
\hline Size $4,10 \mathrm{~mm}$, PS & Size $3,10 \mathrm{~mm}$, PS & Size $9,10 \mathrm{~mm}, \mathrm{PS}$ & Size $5,13 \mathrm{~mm}, \mathrm{CR}$ & Size $5-6,11 \mathrm{~mm}, \mathrm{CR}$ \\
\hline Size $4,12 \mathrm{~mm}$, PS & Size $4,12.5 \mathrm{~mm}$, PS & Size $11,8 \mathrm{~mm}, \mathrm{CR}$ & Size $6,9 \mathrm{~mm}$, PS & Size $5-6,13 \mathrm{~mm}$, PS \\
\hline
\end{tabular}

$\mathrm{PS}=$ posterior stabilized; $\mathrm{CR}=$ cruciate retaining.

authors (ZWS and MGT) visually examined the insert backsurfaces. Both examiners scored individual damage modes and damage score for each insert. The visual damage mode and damage score for each insert then were reported as a mean of the two examiners' scores. Intraclass correlation coefficient for visual scoring between observers was 0.66 (95\% CI, 0.39-0.92), considered good interrater agreement.

Each polyethylene insert then underwent scanning with laboratory micro-CT under a protocol established by Teeter et al. [43], and were compared with unused scanned polyethylene inserts of the same thickness and size by the particular manufacturer: (1) DePuy, (2) Stryker, or (3) Smith \& Nephew [40]. This method has proven to measure backside linear wear rate $(\mathrm{mm} /$ year) or volumetric wear precisely with deviations between 0.4 and $10 \mu \mathrm{m}$ [41] and with a mean absolute accuracy up to one-fifth of the measured voxel spacing of the CT scanner [19, 32, 42]. All retrieved and never-implanted inserts obtained from the respective manufacturers were imaged with an isotropic voxel spacing of $50 \mu \mathrm{m}$ and beam energy of $90 \mathrm{kVp}$ and 40 $\mathrm{mA}$. Scan volumes were reconstructed at full spacing, and the entire tibial insert geometry was generated with isosurface rendering. A previously described surface extraction method then isolated the backsurface of each polyethylene and imported this information to dimensioning software (Geomagic Qualify ${ }^{\circledR}$, 3D Systems, Research Triangle Park, NC, USA) where each retrieved insert backside was registered against the never-implanted backsurface of the same size [41]. Deviations between the two geometries were mapped across the backside (Fig. 2). The greatest negative deviation was determined for each 


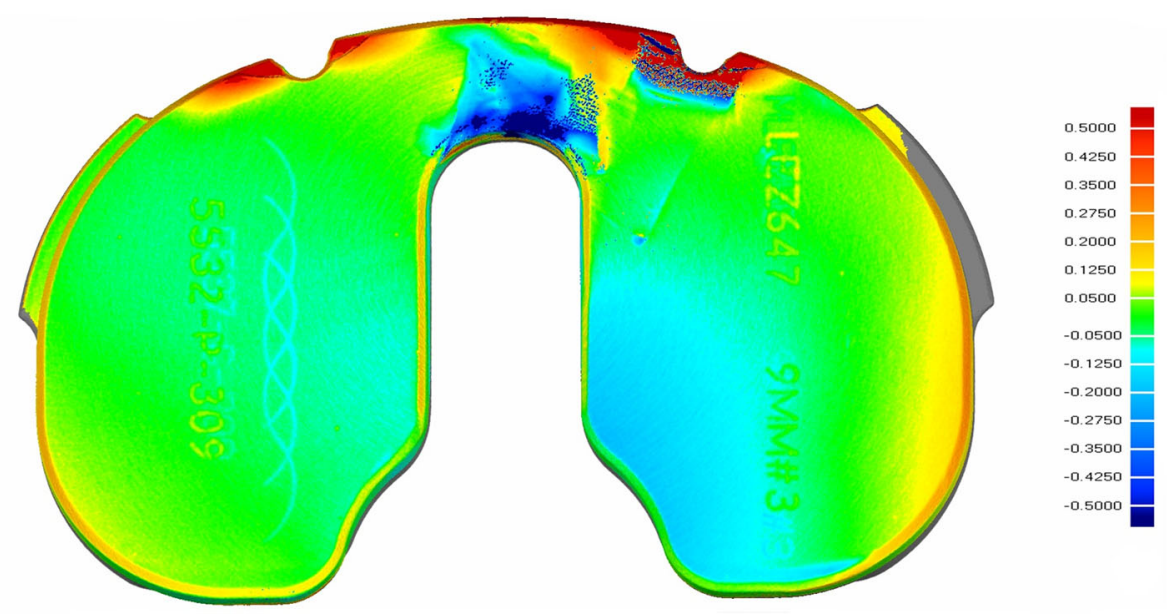

Fig. 2 An example of a deviation map for linear wear rate ( $\mathrm{mm} / \mathrm{year}$ ) for one of the backsurfaces of a retrieved Triathlon polyethylene insert generated from micro-CT scanning is shown. The color bar on

retrieved insert and then was recorded as linear wear (penetration) rate (mm/year), where the distance for maximum negative penetration was recorded per time in vivo in years. Positive deviation corresponded to polyethylene cold flow.

Demographics between groups were compared by oneway ANOVA. Continuous variables are provided as a median with range and $95 \%$ CI. Primary study outcomes were median visual total damage score, individual visual damage modes, and linear wear rate calculated by microCT. Damage modes and damage score per quadrant for the inserts were not compared between groups in this study. Outcomes were compared among all groups with KruskalWallis testing, while outcomes between each group were compared with Dunn's multiple comparison test. Spearman correlations were used for damage scores, linear wear rate, time in vivo, patient age, BMI, sex, and insert thickness. We set statistical significance at a probability less than 0.05 . Using a previous study by Teeter et al. [40] as a reference, for an ANOVA with five groups and comparing six implants per group, we could detect differences in damage scores and damage modes between groups for 10 points or more and differences in wear rate of $0.11 \mathrm{~mm}$ per year or more at a power of $80 \%$. GraphPad Prism Version 7 (GraphPad Software Inc, San Diego, CA, USA) was used for statistical analysis.

\section{Results}

The polished tibial design with a partial peripheral capture locking mechanism with anterior constraint (Genesis II) had a lower total damage score compared with the the right indicates linear wear in $\mathrm{mm}$ per year. Positive wear rates correlate with cold flow. Damage from extraction can be seen along the anterior edge of the retrieved polyethylene that was not analyzed.

Table 4. Total damage scores

\begin{tabular}{|c|c|c|c|}
\hline Implant & Median & Range & $95 \% \mathrm{CI}$ \\
\hline $\mathrm{AMK}^{\mathbb{R}}$ & 15.0 & $9.0-23.0$ & $10.6-20.3$ \\
\hline Sigma $^{\circledR}$ & 15.0 & $10.0-20.0$ & $11.1-18.7$ \\
\hline Scorpio $^{\circledR}$ & $22.3 *$ & $15.5-27.0$ & $17.5-26.5$ \\
\hline Triathlon ${ }^{\circledR}$ & 15.0 & $12.0-19.0$ & $12.3-17.9$ \\
\hline Genesis ${ }^{\mathbb{R}}$ II & $12.5^{*}$ & $9.5-18.0$ & $9.6-16.4$ \\
\hline
\end{tabular}

*Significance with $\mathrm{p}=0.019$; AMK vs Scorpio: $\mathrm{p}=0.340$; Sigma vs Scorpio: $p=0.265$; Triathlon vs Scorpio: $p=0.244$; all other $p$ values $>0.999$ between groups.

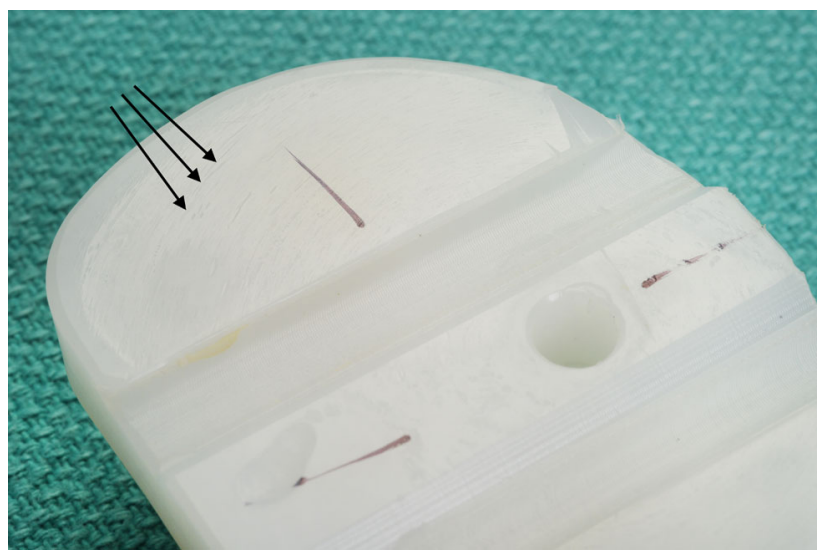

Fig. 3 Abrasions (black arrows) throughout the backsurface of an AMK polyethylene insert are shown.

nonpolished tibial design with only a peripheral-rim locking mechanism (Scorpio) (median, 12.5; range, 9.5-18.0; 95\% CI, 9.58-16.42 versus median, 22.3; range, 15.5-27.0; 
Burnishing

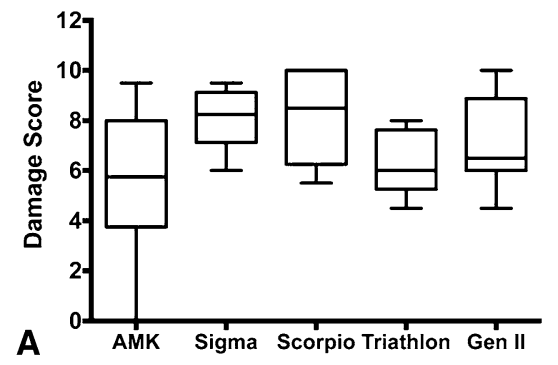

Scratching

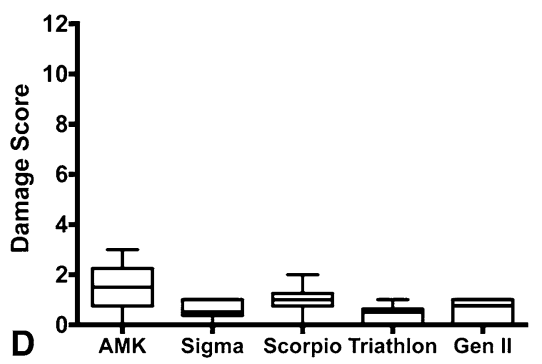

Abrasions

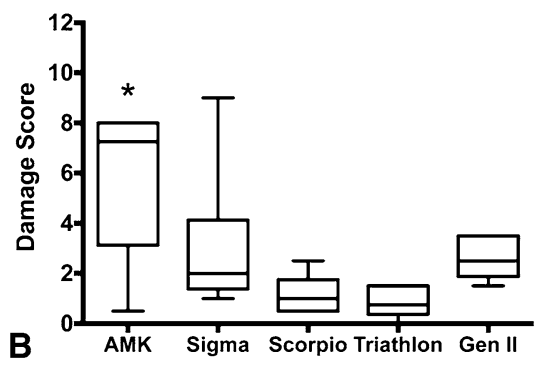

Pitting

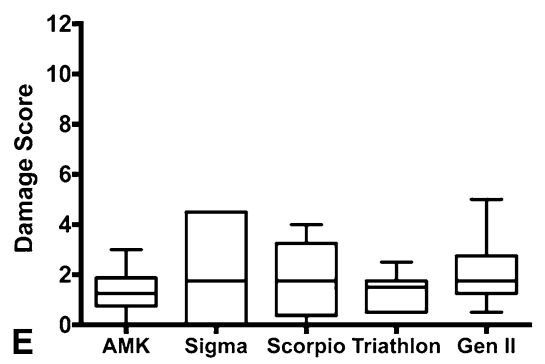

Cold Flow

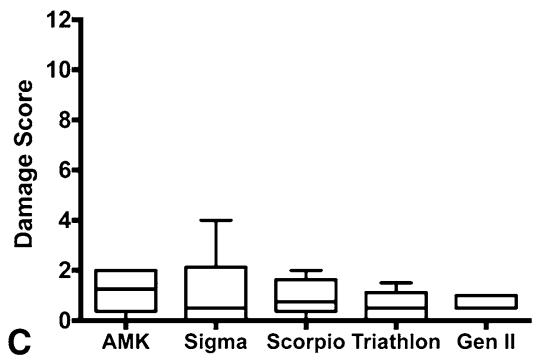

Dimpling

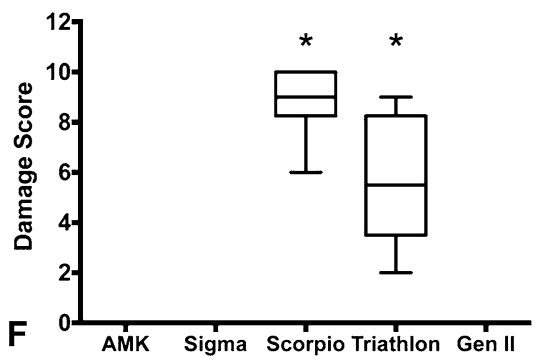

Fig. 4A-F Tibial polyethylene insert median backside visual damage scores for six of the eight individual damage modes are shown. None of the implants showed delamination or embedded debris. The maximum score for each damage mode per insert is 12 (maximum score of 3 for each of the four quadrants). Shown for each of the five designs are: (A) median burnishing; (B) median abrasions, with a difference between the AMK and Triathlon groups (median, 7.25; range, $0.5-8.0$; 95\% CI, 2.67-8.99 versus median, 0.75 ; range, $0-1.5$;

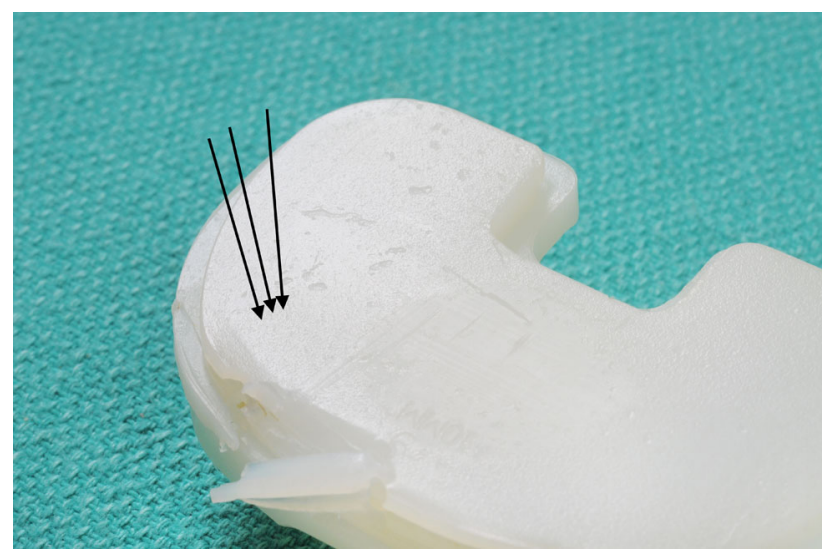

Fig. 5 Dimpling (small divots by multiple black arrows) throughout the back surface of a Scorpio insert is shown.

95\% CI, 17.5-26.5; $\mathrm{p}=0.019)$. Otherwise, the mean total damage scores were not different, with the numbers available, between any other groups (Table 4).

The polished design with a tongue-in-groove locking mechanism (AMK) showed more abrasive wear (Fig. 3) than the nonpolished tibial baseplate design with peripheral-rim capture and central antirotational island
95\% CI, 0.20-1.47; p = 0.016); (C) median cold flow; (D) median scratching; (E) median pitting; and (F) median dimpling, with dimpling only seen in the nonpolished group, so each of the polished baseplate designs (AMK, Sigma, and Genesis II [Gen II]) showed lower scores than the Triathlon (median, 0 versus median, 5.5; range, 2.0-9.0; 95\% CI, 2.96-8.38; $\mathrm{p}=0.048$ ) and Scorpio (median, 0 versus median, 9.0; range, 6.0-10.0; 95\% CI, 7.29-10.38; $\mathrm{p}=0.001$ ). Error bars $=$ range; $*$ significance among the groups for the damage modes.

(Triathlon) (median, 7.25; range, 0.5-8.0; CI, 2.67-8.99 versus median, 0.75 ; range, $0-1.5 ; 95 \% \mathrm{CI}, 0.20-1.47$; $\mathrm{p}=$ 0.016) (Fig. 4), but was not different compared with the (nonpolished) Scorpio design (median, 7.25; range, 0.58.0; 95\% CI, 2.67-8.99 versus median, 1.0; range, 0.5-2.5; 95\% CI, 0.38-1.96; $\mathrm{p}=0.494$ ). Only the two designs with nonpolished tibial baseplates (Triathlon and Scorpio) showed dimpling (Fig. 5). The polished baseplate groups (AMK, Sigma, and Genesis II) showed less dimpling than the Triathlon (median, 0 versus median 5.5; range, 2.0-9.0; 95\% CI, 2.96-8.38; $\mathrm{p}=0.048$ ) and Scorpio (median, 0 versus median 9.0; range, 6.0-10.0; 95\% CI, 7.29-10.38; p $=0.001)$. However, there was no difference in dimpling between the two nonpolished Triathlon and Scorpio designs (median, 5.5; range, 2.0-9.0; 95\% CI, 2.96-8.38 versus median, 9.0; range, 6.0-10.0; 95\% CI, 7.29-10.38; $\mathrm{p}$ $>0.999)$. No other differences were identified when examining burnishing, cold flow, scratching, or pitting between groups. No polyethylene components showed embedded debris or delamination.

Lower overall wear rates were observed on micro-CT for polished compared with nonpolished designs $(0.0102 \pm$ $0.0044 \mathrm{~mm} /$ year versus $0.0224 \pm 0.0119 \mathrm{~mm} /$ year; $\mathrm{p}<$ 
Table 5. Linear wear rates

\begin{tabular}{|c|c|c|c|}
\hline Implant & $\begin{array}{l}\text { Median } \\
\text { (mm/year) }\end{array}$ & $\begin{array}{l}\text { Range } \\
\text { (mm/year) }\end{array}$ & $95 \% \mathrm{CI}$ \\
\hline AMK & -0.0 & -0.005 to -0.015 & 45 to -0.013 \\
\hline Sigma ${ }^{\circledR}$ & -0.015 & -0.007 to -0.018 & -0.0095 to -0.0178 \\
\hline Scorpio ${ }^{\circledR}$ & $-0.025^{*, \#}$ & -0.014 to -0.046 & -0.0130 to -0.0414 \\
\hline Triathlon ${ }^{\circledR}$ & -0.0195 & -0.008 to -0.035 & -0.0097 to -0.0300 \\
\hline Genesis ${ }^{\circledR}$ II & $-0.0083^{*}$ & -0.0038 to -0.0111 & -0.0050 to -0.0107 \\
\hline
\end{tabular}

*Significance with $\mathrm{p}=0.008$; ${ }^{\text {significance with } \mathrm{p}=0.032 ; \mathrm{AMK} \text { vs }}$ Triathlon: $p=0.268$; Genesis II vs Sigma: $p=0.638$; Genesis II vs Triathlon: $\mathrm{p}=0.091$; all other $\mathrm{p}$ values $>0.999$ between groups.

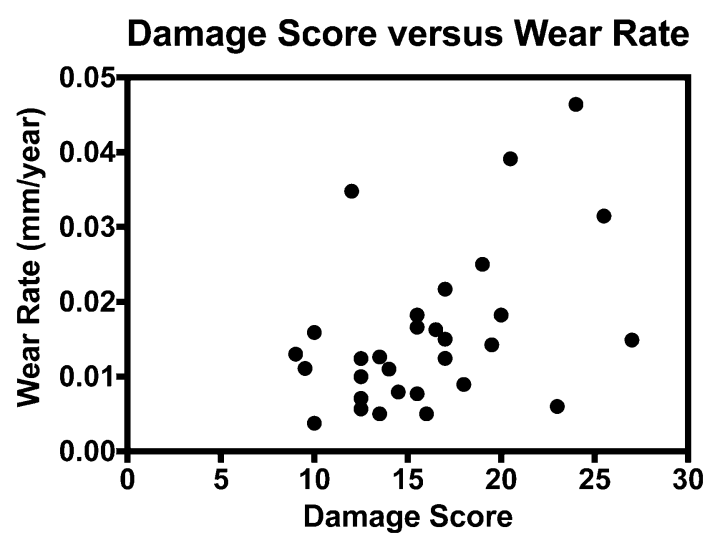

Fig. 6 The correlation between total visual damage score and linear wear rate $(\mathrm{mm} / \mathrm{year})$ determined from micro-CT for all inserts analyzed $(\mathrm{y}=0.001 \mathrm{x}-0.007 ; \mathrm{r}=0.205 ; \mathrm{p}=0.012)$ is shown.

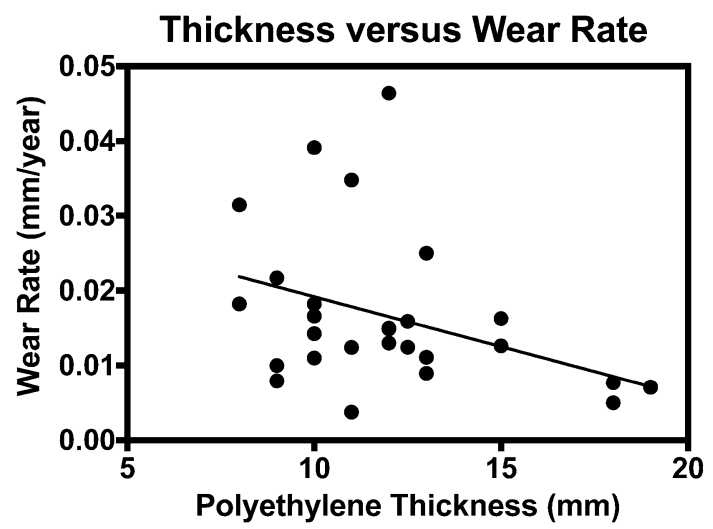

Fig. 7 The correlation between polyethylene insert thickness (mm) and linear wear rate.

0.001). When considering individual designs, the highest wear rates were observed in the nonpolished Scorpio design with only a peripheral-rim capture. The polished Genesis II (median, $0.0083 \mathrm{~mm} /$ year; range, 0.0038$0.0111 \mathrm{~mm} /$ year; 95\% CI, 0.0050-0.0107 $\mathrm{mm}$ versus median, $0.0245 \mathrm{~mm} /$ year; range, 0.014-0.046 mm/year;
95\% CI, 0.0130-0.0414 mm; p = 0.008) and AMK (median, $0.0085 \mathrm{~mm} /$ year; range, $0.005-0.015 \mathrm{~mm} /$ year; $95 \%$ CI, $0.0045-0.0138 \mathrm{~mm}$ versus median, $0.0245 \mathrm{~mm} /$ year; range, 0.014-0.046 $\mathrm{mm} /$ year; 95\% CI, 0.0130-0.0414 mm; $\mathrm{p}=0.031)$ designs showed lower wear rates compared with the nonpolished Scorpio (Table 5). Linear wear rates for the remaining polished (Sigma) and nonpolished (Triathlon) designs did not show a difference when compared with the other groups.

Our cohort did show a correlation between total visual damage score and linear wear rate $(r=0.41 ; \mathrm{p}=0.02)$ (Fig. 6). Furthermore, a correlation was noted with increased linear wear rate and decreasing polyethylene thickness $(r=-0.42 ; p=0.02)$ (Fig. 7). There was no correlation between time in vivo and backside damage scores $(\mathrm{r}=0.13 ; \mathrm{p}=0.50)$ or wear rates $(\mathrm{r}=0.10 ; \mathrm{p}=$ $0.58)$, or when examining BMI versus backside damage scores $(\mathrm{r}=0.002 ; \mathrm{p}=0.99)$ or wear rates $(\mathrm{r}=0.36 ; \mathrm{p}=$ 0.07). Inserts extracted from female patients had higher backside damage scores compared with males (17.2 \pm 4.4 versus $14.1 \pm 4.6 ; \mathrm{p}=0.047)$, but no difference in wear rate $(0.017 \pm 0.012 \mathrm{~mm} /$ year versus $0.013 \pm 0.008 \mathrm{~mm} /$ year; $\mathrm{p}=0.20)$.

\section{Discussion}

Multiple studies have examined the influence of TKA implant design on backside polyethylene damage and wear $[1-4,7,8,10,12,16-18,21,26,27,29-31,36,39$, 40,

44-46]. Historically, some of the strongest contributors are increased tibial baseplate roughness and ability of the locking mechanism to restrict tibial baseplate motion, although many of these studies involve older TKA implants. Our study aimed to analyze whether backside damage and wear were similarly influenced by these variables comparing four modern TKA implant designs and one historical design. While the nonpolished baseplate design with only a peripheral-rim capture (Scorpio) showed higher backside damage scores and linear wear rates, we found comparable results in the other nonpolished group with the addition of a central antirotational island to a peripheral-rim locking mechanism (Triathlon) and the polished designs.

This study has several limitations. Regarding our study design, there was a relatively small number of implants per group. As noted, with the numbers available we would be able to find a difference between groups for a difference in backside damage scores of 10 and linear wear rate of 0.11 $\mathrm{mm}$ per year. However, there is a possibility our study is underpowered to detect clinically significant differences, especially regarding the Genesis II with its polished titanium baseplate and robust locking mechanism that showed 
favorable backside damage scores and wear rates in our analysis. To decrease variability, each cohort was matched based on time in vivo, patient age at explantation, BMI, sex, revision number, and reason for revision surgery. All of these factors could possibly influence backside damage and wear. As for visual assessment of damage score and modes, there is the possibility of introducing bias as we were unable to blind the two examiners to the polyethylene design analyzed. Regardless, our intraclass correlation coefficient graded interobserver reliability as good and there was a positive correlation between our visual backside damage scoring and micro-CT generated linear wear rates, which suggested our visual analysis was adequate.

Additionally, there are limitations when taking into account differences in the polyethylene inserts and tibial baseplates between groups. Our cohorts included combinations of posterior-stabilized and cruciate-retaining polyethylene designs along with different size and thickness polyethylene inserts (Table 3). The relevance of these differences is questionable, as retrieval and biomechanical studies have not found differences between backside wear in posterior-stabilized and cruciate-retaining polyethylene inserts [4, 18], although there is evidence that increasing conformity on the articular polyethylene surface increases backside wear [36]. Similarly, polyethylene size and thickness previously have not shown consistent contributions to backside wear and damage $[8,40]$, therefore, they were not matched between our cohorts, although a correlation was found in our study. Furthermore, the polyethylene formulation, manufacturing techniques, sterilization process, and storage periods admittedly are different between the tibial inserts for each design and can cause difference in wear characteristics [27]. To attempt to minimize such variables, we attempted to ensure inserts with the same characteristics were analyzed for that particular cohort. Thus, all inserts were inertly sterilized and noncrosslinked, except for one polyethylene insert analyzed in the Triathlon group. Undoubtedly, such differences in these polyethylene characteristics could contribute to differences in backsurface damage and wear [6], although a previous study showed factors inherent to the polyethylene are likely less of an influence than baseplate roughness [40]. Similarly there are differences in the composition of the tibial baseplate designs investigated, as they are manufactured from either cobalt-chrome or titanium alloy (Table 2). While titanium has shown better backside wear characteristics in retrieval and biomechanical simulations compared with cobalt-chrome [3, 7], again the tibial baseplate roughness appears to be of more importance for determining the amount of backside insert damage and wear $[3,18,31]$. Nonetheless, the baseplate composition must be mentioned as another variable that influences backside wear and damage.
When examining backside visual damage scores and penetration, we did find the polished baseplate design with a partial peripheral capture locking mechanism and anterior constraint (Genesis II) had less damage and a lower linear wear rate when compared with one of the nonpolished baseplate designs (Scorpio). The polished baseplate design with a tongue-in-groove locking mechanism (AMK) also showed less linear wear than the nonpolished Scorpio. While backside two-dimensional visual total damage scores and three-dimensional micro-CT linear wear rates were positively correlated in our study, this finding has not necessarily been the case in previous analyses $[23,40]$. The results shown by the Scorpio retrievals concur with those of other studies that analyzed the influence of baseplate roughness on backside wear. Teeter et al. [40] found tibial baseplate roughness contributed more to backside damage and wear than polyethylene sterilization method for retrieved inserts from a single design (AMK). In the study by Teeter et al. [40], baseplate roughness showed twice the effect on damage magnitude and polyethylene backside penetration from micro-CT measures when compared with the difference between polyethylenes undergoing sterilization with gas plasma versus gamma irradiation in air. In another study, Abdel et al. [1] reported that a highly polished tibial tray (Genesis II) reduced backside damage compared with the nonpolished Optetrak ${ }^{\circledR}$ Primary Knee System (Exactech, Gainesville, FL, USA) or the nonpolished NexGen ${ }^{\circledR}$ Total Knee System (Zimmer, Warsaw, IN, USA). Berry et al. [4] found similar results when comparing polished and nonpolished baseplates of a singlebearing design (Sigma), as tibial insert backsides from nonpolished baseplates showed increased penetration. In addition to these findings from retrieval studies, biomechanical analyses echo these results as two studies showed up to 20 times as many polyethylene backside wear particles generated in designs with nonpolished tibial baseplates compared with polished designs $[3,18]$. The importance of polishing is highlighted by the decreased wear rate of the AMK when compared with the Scorpio despite the poor locking mechanism design of the AMK $[15,30]$.

As opposed to the expected backside damage and wear shown by the Scorpio, the other nonpolished baseplate design in our study (Triathlon) did not show a difference in either overall damage scoring or penetration rate compared with the Genesis II or any other polished designs. The difference between the two nonpolished TKA implant designs lies in the addition of a central antirotational island to the peripheral capture in the Triathlon design that may decrease backside motion and thereby potentially mitigate the effect of baseplate roughness on backside wear. The importance of locking mechanism strength is underscored in previous analyses of multiple implants that showed locking mechanisms in all designs loosened with time 
$[15,30]$. Rao et al. [31] subsequently found that the amount of visual backside wear directly correlated with the amount of insert motion. Furthermore, Billi et al. [3], in biomechanical testing, similarly showed that increasing backside motion amplitude from 50 to $200 \mu \mathrm{m}$ in a blasted titanium baseplate surface can cause a fourfold increase in polyethylene backside wear. Certain types of locking mechanisms also have been implicated with improved backside wear, as peripheral capture designs show less wear [2] compared with tongue-in-groove designs [7] or locking clips [10]. However, most of the implants analyzed in these studies examined implant designs not currently manufactured and with poor locking mechanisms predating peripheral-rim captures. In particular, to our knowledge, no studies have evaluated a full peripheral capture design with an antirotational island and its influence on backside wear.

A few different modes of wear were observed between groups on visual damage scoring. More abrasive wear was seen on the polished design with a tongue-in-groove locking mechanism (AMK) compared with the nonpolished Triathlon design. This damage pattern was unsurprising, as Conditt et al. [7] previously showed tongue-in-groove locking mechanisms are less effective than a peripheral capture at limiting backside motion in line with the linear grooves of the capture. In addition to classic wear modes described by Hood et al. [22], we found the insert backsides of the nonpolished baseplates had an additional wear mode, dimpling, that was not observed with any polished baseplate designs. Harmon et al. [21] similarly described dimpling as a common wear mode in a nonpolished TKA baseplate design (Series $7000^{\mathbb{R}}$ Tibial Tray, Stryker Orthopaedics, Kalamazoo, MI, USA), analogous to the Scorpio baseplate, with a peripheral rim snap-fit locking mechanism consisting of a circumferential tibial traylipped edge and three anterior metal barbs.

Our combined cohorts did show a correlation between total visual damage score and linear wear rate, which is different than reported by Teeter et al. [40] who found no correlation in the AMK. Decreased polyethylene thickness correlated with increased backside linear wear rate in our study. This finding differs from previous analyses in which thickness had no effect on linear wear [10, 40] or damage [8]. There are various findings regarding the influence of time in vivo on backside damage and wear, with multiple studies showing a positive correlation between increased time in vivo and increased wear $[4,17,21,31,44]$ and other studies showing no difference $[1,10,27,40]$. Similarly, BMI has a questionable association with backside damage and wear with some studies supporting its influence $[7,8,44]$ and others showing no effect $[1,2,7,10,21,40]$.

Overall, we observed that total visual damage scores and linear wear rates were not different, with the numbers available, between implant groups except for the nonpolished design with only a peripheral-rim capture (Scorpio).
However, the other nonpolished baseplate design (Triathlon) has a more-robust locking mechanism that may explain no difference in the damage scores and linear wear rates, with the numbers available, compared with the polished baseplate designs. Such improvements in the locking mechanism with a nonpolished design, presumably leading to a decrease in insert micromotion, could offset some of the advantages of polished baseplate surfaces, although this needs to be evaluated further in future studies. Dimpling wear patterns appeared specific to nonpolished tibial baseplates while abrasive wear patterns were identified in the historical tongue-in-groove locking mechanism design. Furthermore, in the historical design that no longer is in use, it was an interesting finding that a polished baseplate but a relatively weak locking mechanism exhibited comparable backside wear to the other designs, with the numbers available. Our study showed that in the complex interplay between baseplate surface finish and locking mechanism design, a polished baseplate with a robust locking mechanism had the lowest backside damage and linear wear.

\section{References}

1. Abdel MP, Gesell MW, Hoedt CW, Meyers KN, Wright TM, Haas SB. Polished trays reduce backside wear independent of post location in posterior-stabilized TKAs. Clin Orthop Relat Res. 2014;472:2477-2482.

2. Azzam MG, Roy ME, Whiteside LA. Second-generation locking mechanisms and ethylene oxide sterilization reduce tibial insert backside damage in total knee arthroplasty. $J$ Arthroplasty. 2011;26:523-530.

3. Billi F, Sangiorgio SN, Aust S, Ebramzadeh E. Material and surface factors influencing backside fretting wear in total knee replacement tibial components. J Biomech. 2010;43:1310-1315.

4. Berry DJ, Currier JH, Mayor MB, Collier JP. Knee wear measured in retrievals: a polished tray reduces insert wear. Clin Orthop Relat Res. 2012;470:1860-1868.

5. Collier JP, Sperling DK, Currier JH, Sutula LC, Saum KA, Mayor MB. Impact of gamma sterilization on clinical performance of polyethylene in the knee. $J$ Arthroplasty. 1996;11:377-389.

6. Collier MB, Engh CA Jr, McAuley JP, Ginn SD, Engh GA. Osteolysis after total knee arthroplasty: influence of tibial baseplate surface finish and sterilization of polyethylene insert. Findings at five to ten years postoperatively. J Bone Joint Surg Am. 2005;87:2702-2708.

7. Conditt MA, Stein JA, Noble PC. Factors affecting the severity of backside wear of modular tibial inserts. J Bone Joint Surg Am. 2004;86:305-311.

8. Conditt MA, Thompson MT, Usrey MM, Ismaily SK, Noble PC. Backside wear of polyethylene tibial inserts: mechanism and magnitude of material loss. J Bone Joint Surg Am. 2005;87:326331.

9. Costa L, Luda MP, Trossarelli L, Brach del Prever EM, Crova M, Gallinaro P. Oxidation in orthopaedic UHMWPE sterilized by gamma-radiation and ethylene oxide. Biomaterials. 1998;19:659668.

10. Cuckler JM, Lemons J, Tamarapalli JR, Beck P. Polyethylene damage on the nonarticular surface of modular total knee prostheses. Clin Orthop Relat Res. 2003;410:248-253. 
11. Engh GA, Ammeen DJ. Session II: Polyethylene wear. Clin Orthop Relat Res. 2002;404:71-74.

12. Engh GA, Ammeen DJ. Epidemiology of osteolysis: backside implant wear. Instr Course Lect. 2004;53:243-249.

13. Engh GA, Dwyer KA, Hanes CK. Polyethylene wear of metalbacked tibial components in total and unicompartmental knee prostheses. J Bone Joint Surg Br. 1992;74:9-17.

14. Engh GA, Koralewicz LM, Pereles TR. Clinical results of modular polyethylene insert exchange with retention of total knee arthroplasty components. J Bone Joint Surg Am. 2000;82:516523.

15. Engh GA, Lounici S, Rao AR, Collier MB. In vivo deterioration of tibial baseplate locking mechanisms in contemporary modular total knee components. J Bone Joint Surg Am. 2001;83:16601665.

16. Fehring TK, Murphy JA, Hayes TD, Roberts DW, Pomeroy DL, Griffin WL. Factors influencing wear and osteolysis in press-fit condylar modular total knee replacements. Clin Orthop Relat Res. 2004;428:40-50.

17. Gabriel SM, Dennis DA, Honey MJ, Scott RD. Polyethylene wear on the distal tibial insert surface in total knee arthroplasty. Knee. 1998;5:221-228.

18. Galvin A, Jennings LM, McEwen HM, Fisher J. The influence of tibial tray design on the wear of fixed-bearing total knee replacements. Proc Inst Mech Eng H. 2008;222:1289-1293.

19. Gelaude F, Vander Sloten J, Lauwers B. Accuracy assessment of CT-based outer surface femur meshes. Comput Aided Surg. 2008;13:188-199.

20. Gioe TJ, Killeen KK, Grimm K, Mehle S, Scheltema K. Why are total knee replacements revised?: analysis of early revision in a community knee implant registry. Clin Orthop Relat Res. 2004;428:100-106.

21. Harman MK, Banks SA, Hodge WA. Backside damage corresponding to articular damage in retrieved tibial polyethylene inserts. Clin Orthop Relat Res. 2007;458:137-144.

22. Hood RW, Wright TM, Burstein AH. Retrieval analysis of total knee prostheses: a method and its application to 48 total condylar prostheses. J Biomed Mater Res. 1983;17:829-842.

23. Knowlton CB, Bhutani P, Wimmer MA. Relationship of surface damage appearance and volumetric wear in retrieved TKR polyethylene liners. J Biomed Mater Res B Appl Biomater. 2016 June 12. [Epub ahead of print] doi: 10.1002/jbm.b.33684.

24. Kurtz SM, Gawel HA, Patel JD. History and systematic review of wear and osteolysis outcomes for first-generation highly crosslinked polyethylene. Clin Orthop Relat Res. 2011;469:22622277.

25. Kurtz SM, Muratoglu OK, Evans M, Edidin AA. Advances in the processing, sterilization, and crosslinking of ultra-high molecular weight polyethylene for total joint arthroplasty. Biomaterials. 1999;20:1659-1688.

26. Li S, Scuderi G, Furman BD, Bhattacharyya S, Schmieg JJ, Insall JN. Assessment of backside wear from the analysis of 55 retrieved tibial inserts. Clin Orthop Relat Res. 2002;404:75-82.

27. Lombardi AV Jr, Ellison BS, Berend KR. Polyethylene wear is influenced by manufacturing technique in modular TKA. Clin Orthop Relat Res. 2008;466:2798-2805.

28. O'Rourke MR, Callaghan JJ, Goetz DD, Sullivan PM, Johnston RC. Osteolysis associated with a cemented modular posteriorcruciate-substituting total knee design: five to eight-year followup. J Bone Joint Surg Am. 2002;84:1362-1371.

29. Pang HN, Jamieson P, Teeter MG, McCalden RW, Naudie DD, MacDonald SJ. Retrieval analysis of posterior stabilized polyethylene tibial inserts and its clinical relevance. $J$ Arthroplasty. 2014;29:365-368.

30. Parks NL, Engh GA, Topoleski LD, Emperado J. The Coventry Award: Modular tibial insert micromotion: a concern with contemporary knee implants. Clin Orthop Relat Res. 1998;356:10 15.

31. Rao AR, Engh GA, Collier MB, Lounici S. Tibial interface wear in retrieved total knee components and correlations with modular insert motion. J Bone Joint Surg Am. 2002;84:1849-1855.

32. Rathnayaka K, Sahama T, Schuetz MA, Schmutz B. Effects of CT image segmentation methods on the accuracy of long bone 3D reconstructions. Med Eng Phys. 2011;33:226-233.

33. Robinson EJ, Mulliken BD, Bourne RB, Rorabeck CH, Alvarez C. Catastrophic osteolysis in total knee replacement: a report of 17 cases. Clin Orthop Relat Res. 1995;321:98-105.

34. Rodriguez JA, Baez N, Rasquinha V, Ranawat CS. Metal-backed and all polyethylene tibial components in total knee replacement. Clin Orthop Relat Res. 2001;392:174-183.

35. Schroer WC, Berend KR, Lombardi AV, Barnes CL, Bolognesi MP, Berend ME, Ritter MA, Nunley RM. Why are total knees failing today? Etiology of total knee revision in 2010 and 2011. J Arthroplasty. 2013;28(8 suppl):116-119.

36. Schwarzkopf R, Scott RD, Carlson EM, Currier JH. Does increased topside conformity in modular total knee arthroplasty lead to increased backside wear? Clin Orthop Relat Res. 2015;473:220-225.

37. Sharkey PF, Hozack WJ, Rothman RH, Shastri S, Jacoby SM. Insall Award paper: Why are total knee arthroplasties failing today? Clin Orthop Relat Res. 2002;404:7-13.

38. Sharkey PF, Lichstein PM, Shen C, Tokaraski AT, Parvizi J. Why are total knee arthroplasties failing today: has anything changed after 10 years? J Arthroplasty. 2014;29:1774-1778.

39. Surace MF, Berzins A, Urban RM, Jacobs JJ, Berger RA, Natarajan RN, Andriacchi TP, Galante JO. Coventry Award paper: Backsurface wear and deformation in polyethylene tibial inserts retrieved postmortem. Clin Orthop Relat Res. 2002;404:14-23.

40. Teeter MG, Lanting BA, Shrestha KR, Howard JL, Vasarhelyi EM. Contribution of surface polishing and sterilization method to backside wear in total knee arthroplasty. $J$ Arthroplasty. 2015;30:2320-2322.

41. Teeter MG, Milner JS, Naudie DD, MacDonald SJ. Surface extraction can provide a reference for micro-CT analysis of retrieved total knee implants. Knee. 2014;21:801-805.

42. Teeter MG, Naudie DD, Bourne RB, Holdsworth DW. How do CAD models compare with reverse engineered manufactured components for use in wear analysis? Clin Orthop Relat Res. 2012;470:1847-1854.

43. Teeter MG, Naudie DD, McErlain DD, Brandt JM, Yuan X, MacDonald SJ, Holdsworth DW. In vitro quantification of wear in tibial inserts using microcomputed tomography. Clin Orthop Relat Res. 2011;469:107-112.

44. Wasielewski RC. The causes of insert backside wear in total knee arthroplasty. Clin Orthop Relat Res. 2002;404:232-246.

45. Wasielewski RC, Galante JO, Leighty RM, Natarajan RN, Rosenberg AG. Wear patterns on retrieved polyethylene tibial inserts and their relationship to technical considerations during total knee arthroplasty. Clin Orthop Relat Res. 1994;299:31-43.

46. Wasielewski RC, Parks N, Williams I, Surprenant H, Collier JP, Engh G. Tibial insert undersurface as a contributing source of polyethylene wear debris. Clin Orthop Relat Res. 1997;345:5359. 